This item was submitted to Loughborough's Research Repository by the author.

Items in Figshare are protected by copyright, with all rights reserved, unless otherwise indicated.

\title{
Electrochemical treatments of corroded reinforcement in concrete
}

PLEASE CITE THE PUBLISHED VERSION

http://dx.doi.org/10.1201/9781439828403.ch110

PUBLISHER

CRC Press (@ Taylor and Francis)

VERSION

AM (Accepted Manuscript)

LICENCE

CC BY-NC-ND 4.0

REPOSITORY RECORD

Christodoulou, Christian. 2019. "Electrochemical Treatments of Corroded Reinforcement in Concrete". figshare. https://hdl.handle.net/2134/10962. 
This item was submitted to Loughborough's Institutional Repository (https://dspace.lboro.ac.uk/) by the author and is made available under the following Creative Commons Licence conditions.

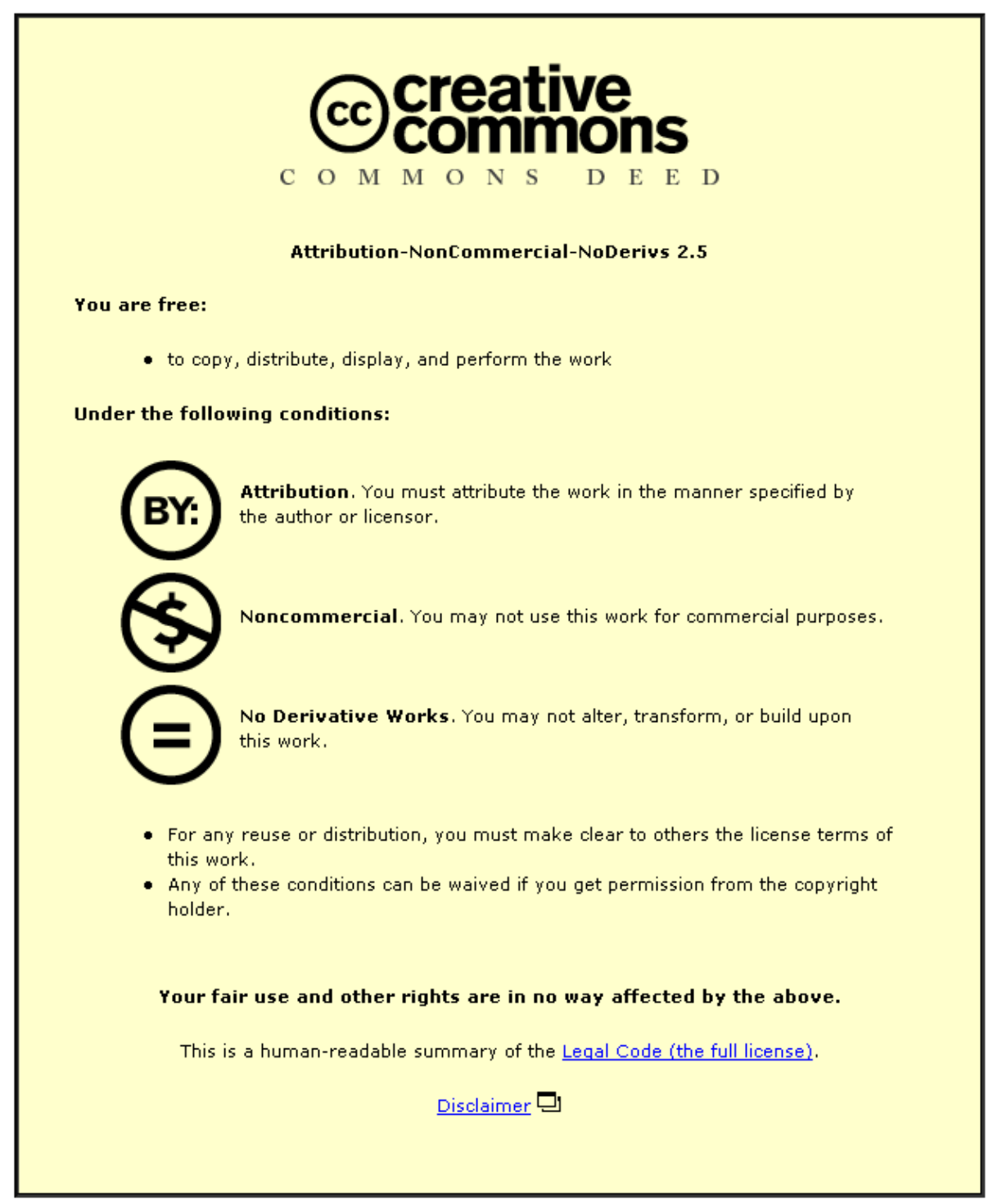

For the full text of this licence, please go to: http://creativecommons.org/licenses/by-nc-nd/2.5/ 


\title{
Electrochemical treatments of corroded reinforcement in concrete
}

\author{
C. Christodoulou \\ Faber Maunsell, Birmingham, B3 1PB, UK, christos.christodoulou@fabermaunsell.com
}

\begin{abstract}
Electrochemical treatment methods have been used to arrest corrosion and protect the serviceable life of a structure. This paper analyses the corrosion initiation mechanisms, the chemical reactions taking place at the steel interface and the transportation process. The available options are briefly discussed and their advantages and disadvantages examined. The conclusions drawn, focus on the current practice and how the discussed electrochemical treatments can be used to optimize performance.
\end{abstract}

\section{INTRODUCTION}

Reinforced concrete structures are widespread throughout the world and exposed to different climate conditions. Corrosion may be induced due to chloride ingress, cast in chloride and carbonation.

Concrete under normal circumstances provides a non-aggressive and highly alkaline environment with $\mathrm{pH}$ above 13 . This is achieved during the hydration process of cement. Under these conditions, the steel remains passive and develops an oxide film which covers its surface and presents a barrier to further metal dissolution (Page \& Tradeaway 1982). A wide range of factors may affect the electrochemical stability of this thin protective film and these are discussed later on. When break out of this film occurs, corrosion will initiate and propagation will be subject to concrete resistivity, humidity, chloride ingress, defects, cracks etc.

\section{CARBONATION}

Carbon Dioxide $\left(\mathrm{CO}_{2}\right)$ and other acidic gases present in the atmosphere can dissolve in the pore water of concrete and form carbonic acid (Concrete Repair Association 2001). The reaction occurs mainly with calcium hydroxide and produces calcium carbonate.

$$
\mathrm{CO}_{2}+\mathrm{Ca}(\mathrm{OH})_{2} \underset{\mathrm{H}_{2} \mathrm{O}}{\rightarrow} \mathrm{CaCO}_{3}+\mathrm{H}_{2} \mathrm{O}
$$

The above reaction severely reduces the $\mathrm{pH}$ to as low as 8 and as a result the passivating oxide film is broken out.

Several studies have shown that concrete surfaces which are protected from rain, suffer from carbona- tion more than exposed structures (Parrott 1987). Diffusion of carbon dioxide both in dry environments and water saturated concrete is a very slow process and reaction 1 cannot be sustained. Carbonation is a common problem for car parks and buildings and typically occurs in medium moist environments with a relative humidity between $50-70 \%$.

Some indicative means to suppress such an action is to specify a low water to cement ratio but with adequate cement content for a complete hydration process (British Standards Institution 1997). The use of paint coatings and plasticisers to increase density and decrease permeability are also very significant. However, the quality of the concrete will dominate the life span without any major maintenance.

\section{CHLORIDES}

Chloride ions may be cast into concrete due to poor construction materials or the use of accelerators. Such problems are not commonly observed in newly built structures and chloride induced corrosion is a direct result of exposure to marine environments, water spray and the penetration of de-icing salts which are applied on the moist surface of the structure during the winter months.

Once the chloride content exceeds a certain limit, known as chloride threshold, corrosion will initiate as a result of the oxide film breakdown (Manning 1985, Everett \& Treadaway 1980). Currently, this limit is expressed in terms of total chloride (bound and free). Measured levels range from 0.2 to more than $2 \%$ by weight of cement. This wide range indicates that corrosion initiation is subject to a number of factors and not only to chloride levels. 


\section{CORROSION INITIATION MECHANISM}

Steel in concrete is normally passive and stable, and under a high alkaline environment it develops a passive oxide protective film. The diagram shown in Figure 1 illustrates the thermodynamic stability of the film in alkalinity. Even in the presence of chlorides, the oxides making up the protective film remain the most stable products and a significant reduction in $\mathrm{pH}$ needs to occur to de-stabilise the steelconcrete system.

Chloride attack tends to be localised and the film breakdown tends to follow the model of pitting corrosion followed by pit growth (Glass 2000). If the pits are to grow, pit nucleation must be followed by a fall in $\mathrm{pH}$ and increase in chloride content at the pit nucleation site. The local fall in $\mathrm{pH}$ will occur from the hydrolysis of dissolving iron ions, as expressed from Equation 2.

$$
\mathrm{Fe}^{2+}+2 \mathrm{H}_{2} \mathrm{O} \rightarrow \mathrm{Fe}(\mathrm{OH})_{2}+2 \mathrm{H}^{+}
$$

The dissolving ions react with water to form iron hydroxides and hydrogen ions (anodic reaction). The remaining free electrons flow through the steel to the cathodic site where they react with dissolved oxygen to form hydroxyl ions $\left(\mathrm{OH}^{-}\right)$. Based on the principle of electroneutrality, charge build up is prevented by the hydroxyls flowing towards the anode and the ferrous ions towards the cathode.

Where they meet they electrically neutralise each other and form ferrous hydroxide $\mathrm{Fe}(\mathrm{OH})_{2}$ which when mixed with oxygen will form haematite $\mathrm{Fe}_{2} \mathrm{O}_{3} \cdot 3 \mathrm{H}_{2} \mathrm{O}$ a by product of the corrosion circle, otherwise known as "red-brown rust".

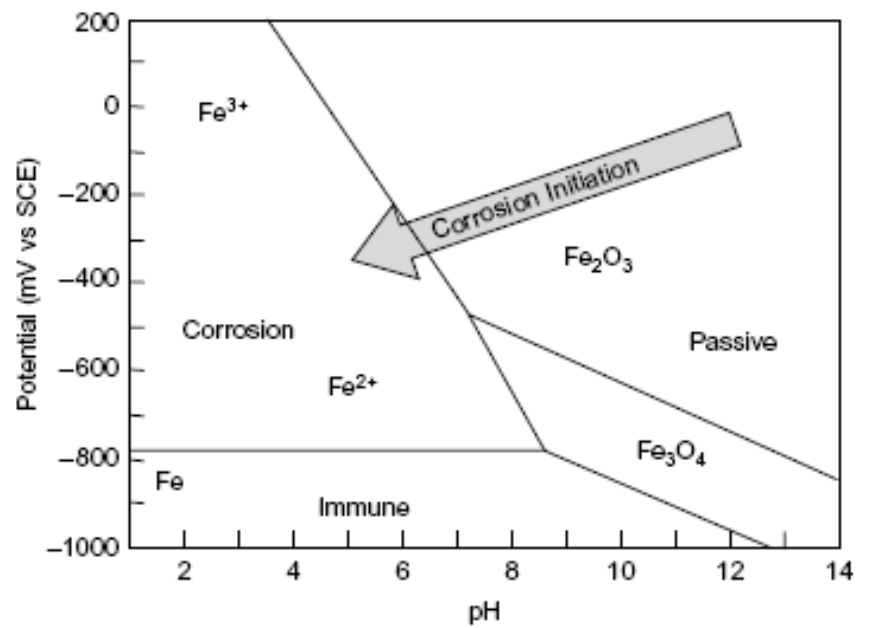

Figure 1: Corrosion initiation arrest mechanism (Glass et al. 2007)

The positively charged ions are balanced at the anode by the presence of negative charged chloride ions, combined to produce hydrochloric acid (Figure 2 ). The amount of oxygen is crucial to sustain the reaction and for submerged structures corrosion will not easily initiate as the supply of oxygen is limited.
However, oxygen deficient reactions are more serious as they tend to develop for a considerable time before any visible evidence. In such cases, the rust may be green which is believed to be a complex chemical composition based on chlorides or black as a product of magnetite $\left(\mathrm{Fe}_{3} \mathrm{O}_{4}\right)$.

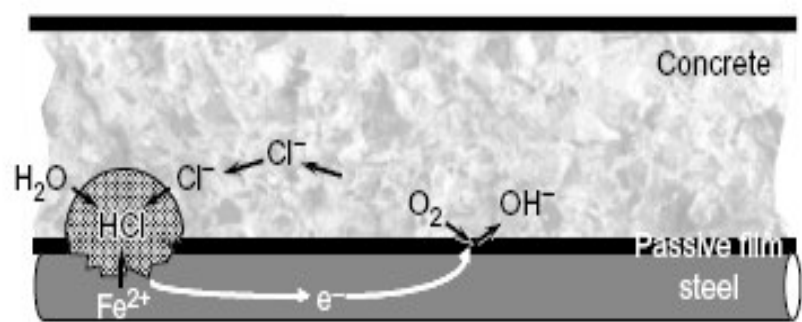

Figure 2: Process of corrosion on steel in concrete (Glass et al. 2006)

\section{TRANSPORT PROCESS}

The main mechanism for chloride ingress into concrete includes water flow, migration in an electric field and diffusion. Diffusion will be controlled by the diffusion coefficient which results in the allowable flux. Water flow will depend on pressure gradients, absorption of dry concrete, capillary forces or electro-osmosis. Finally mitigation is affected by ionic mobility or in other terms the average velocity per unit electric field.

Based on the Nernst-Planck equation (3), the flux of ions through an ideal solution may be expressed as:

$$
J=-D_{p} \frac{\partial C}{\partial x}-v C \frac{\partial \varphi}{\partial x}+C u
$$

where $\mathrm{C}, \mathrm{D}_{\mathrm{p}}, \mathrm{v}, \varphi, \mathrm{u}$ are the concentration, diffusion coefficient, ionic mobility, electric potential and average mass velocity, respectively (Weber et al. 1991).

The spatial distribution of the species may be given by solving equation 4 .

$$
\frac{\partial C}{\partial t}=\frac{\partial J}{\partial x}+r
$$

where $r$ is the rate of production/consumption of the species (Buenfeld et al. 1998).

A series of possible solutions exist making a number of simplifications. Some of them include the assumption of an invariable diffusion coefficient or zero chloride binding. However, chloride binding will take place, diffusion will vary with time and depth of penetration, moisture content will also affect penetration and the surface chloride content will vary with time due to difference in environmental exposure. The principle of electroneutrality also increases the complexity of the process and therefore numerical methods need to be employed to produce 
the solution, which due to its complexity requires substantial computing power. The increasing complexity requires additional parameters which are not always available through field measurements thus, rendering mathematical models prone to inconsistencies and empirical ones used instead.

\section{CHLORIDE THRESHOLD LEVEL}

This may be defined as the critical level after which the concentration of chlorides is sufficient to sustain local breakdown of the passive film and therefore initiate micro-corrosion cells. It is expressed as a ratio of the total chloride to cement content of concrete (i.e. a weight percentage). Based on a variety of researches and literature, typical threshold levels range between 0.2 and $2.5 \%$ by weight of cement (Glass \& Buenfeld 1997). Although chloride levels are easily measured, the cement content can only be estimated as laboratory verification is difficult.

Although bound chlorides will contribute to corrosion development, still there is no sufficient evidence to prove a correlation between the chloride binding and chloride threshold levels (Glass et al. 1999).

During the electrochemical treatment process, it has been observed that sodium silicate gel and calcium hydroxide are by-products of the treatment which will fill the pores and the interface voids of the concrete (Sergi et al. 1991, Marcotte et al. 1999). These will provide a reservoir of hydroxyl ions at the steel which suggests that electrochemical treatments not only arrest corrosion but they also increase the reservoir of $\mathrm{OH}^{-}$which then increases the chloride threshold levels.

\section{CORROSION}

Corrosion rates are usually expressed as a current density, a rate of weight loss or a rate of section loss. A corrosion rate of $1 \mathrm{~mA} / \mathrm{m}^{2}$ is approximately a loss of $10 \mathrm{~g} / \mathrm{m}^{2} /$ year or otherwise a loss of section of $1 \mu \mathrm{m} /$ year. As indicated from Figure 3, rates below 1 or $2 \mathrm{~mA} / \mathrm{m}^{2}$ are considered negligible and corrosion development highly unlikely. Any rate higher than the aforementioned ones may result in the disruption of the concrete cover and passive film breakdown. Local fall in $\mathrm{pH}$ as low as 4 has been observed and the local corrosion rates may exceed $100 \mathrm{~mA} / \mathrm{m}^{2}$ or in some extreme cases exceed $1000 \mathrm{~mA} / \mathrm{m}^{2}$ (Broomfield 1997).

A range of control measures exist to influence corrosion kinetics and the electrons movement. However, the reinforcement has a very low resistivity to the electrons movement and hence a successful arrest mechanism will have to control either the kinetics on the anodic and cathodic sites or by influ- encing the resistance of electrolyte (i.e. concrete) between those sites.

It has been established that moisture levels and temperature will also affect the corrosion rates. At very dry environments and high temperatures chloride ingress is a very slow process, similarly to the dissolved oxygen availability in water saturated environments. Thus, the interior areas of buildings are hardly ever affected by corrosion and it is the exterior that usually needs to be protected.

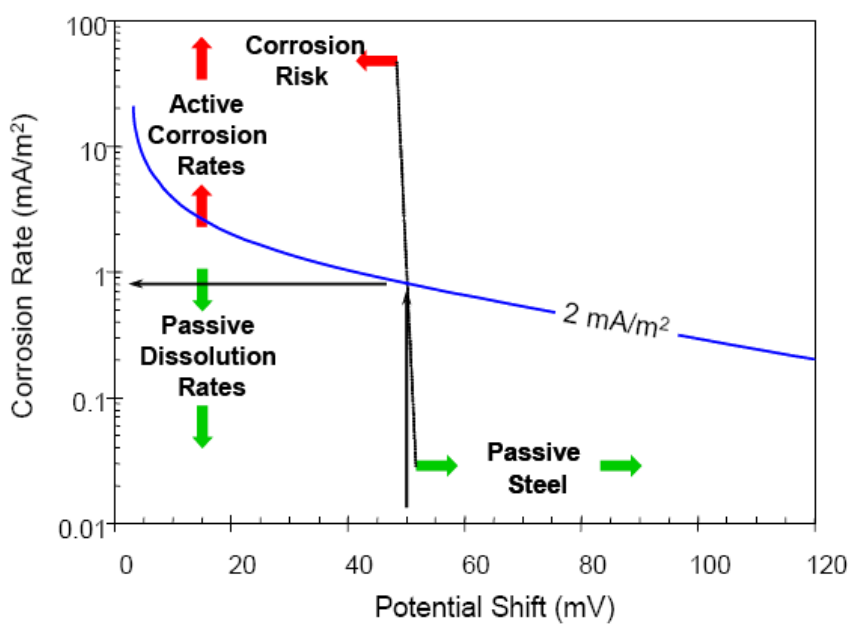

Figure 3: Corrosion rate plotted as a function of potential shift and current density together with an example of its interpretation (Davison et al. 2008).

\section{CONTROL MEASURES}

\subsection{Monitoring corrosion}

This technique may be used to assess the current condition of any structure and determine future deterioration. Cracks along the line of the reinforcement are a clear indication of active corrosion, whereas delamination and spalling are indicative of corrosion products and severe electrochemical reactions currently on-going.

Various techniques to assess corrosion exist, such as corrosion rate measurements, potential mapping and concrete resistivity measurements. Corrosion potential and rate measurements give an indication of the condition of the passive film on the steel (Gowers \& Millard 1999).

\subsection{Patch Repairs}

This is the most traditional method of repair employed the last few decades. However, it is essential to ensure that all contaminated concrete is removed, all surfaces cleaned and rebar exposed to a significant depth to clear corroding sites.

Patch repair mixes need to be cementitious with altered tensile properties, adhesion, water demand and significantly lower shrinkage properties than ordinary concrete. Conventional concrete may only be 
used for a large volume of repairs but caution is needed to ensure a good quality mix, free of bleeding and an adequate bonding.

Zinc in a mortar has also been used, which prevents zinc passivation and is able to accommodate the expansive corrosion products (Page \& Sergi 2000).

In general, carbonated concrete can be successfully replaced and the fresh alkaline mortar will ensure repassivation of the reinforcement. When chloride ingress is responsible for corrosion initiation, it must be ensured that the concrete is removed to a significant depth to produce successful results. Hence, requiring removing a great amount of contaminated but otherwise sound material and rendering the whole process far too expensive.

If levels greater than 0.2 to $0.5 \%$ of chloride ion by mass of concrete remain on the freshly repaired area, the phenomenon of "incipient anode formation" will be observed. As such, the new cathodic area within the repair patch will shift the anodic sites towards the previously cathodic and passive sites and initiate corrosion.

Patch repairs is nowadays an unfavourable solution, as cast in chlorides can not be completely removed and success of the scheme can not be guaranteed.

\subsection{Impressed Current Cathodic Protection}

The principle relies on the passage of an electric current through the electrolyte to the corroding metal surface and reverses the direction of the electric current produced by the corrosion reactions. Therefore, the potential of the metal is shifted to the negative direction. Using reference electrodes, the performance of the system can be assessed by measuring the potential shift.

The differentiation on the cathodic systems may be observed on the type of the anodes used. This can be a conductive coating, a titanium mesh with cementitious overlay, conductive cementitious overlay or discrete anodes.

It is essential that the concrete surface has been thoroughly cleaned from dirt and debris and any visible steel elements such as nails have been removed. The continuity of the electric circuit will be subject to the aforementioned parameters and therefore affect whether the whole of the structure will be protected or only part of it, thus mitigating corrosion.

Direct electrical contact between the anode and the reinforcement will create electrical short circuits which will stop the system from functioning. Also, stray current corrosion of discontinuous steel is possible.

Figure 4 illustrates a typical field application of impressed current cathodic protection using a conductive coating anode.

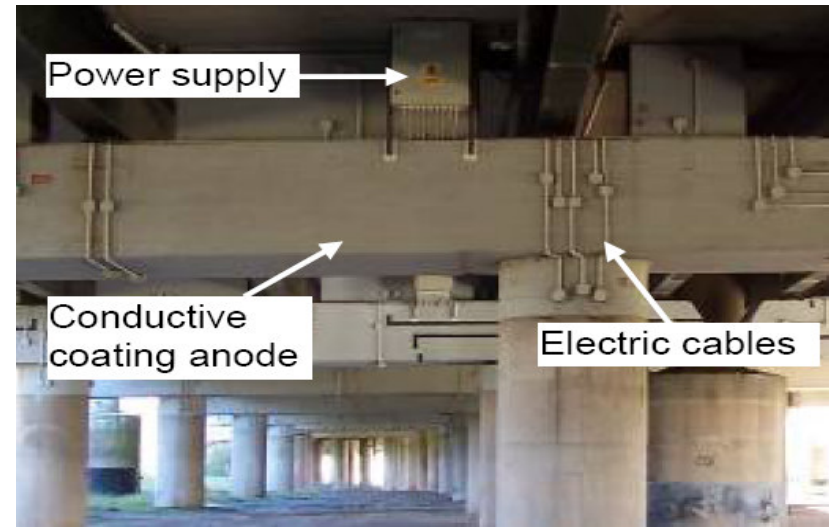

Figure 4: Typical impressed current cathodic protection installation.

Although impressed current cathodic protection is considerably more complex than other methods, the great extent of the wire networking aims to take into account miscellaneous facts such as different layers of reinforcement and varying concrete resistivity throughout the section. Current densities are usually regulated, as if they are too high they can cause reactions on the anode - concrete interface and produce acids, depending on the anode material.

\subsection{Chloride Extraction}

This method contrary to the impressed current cathodic protection is usually applied for a period of 6 to 12 weeks. Typically, a current density of $1000 \mathrm{~mA} / \mathrm{m}^{2}$ is applied. Higher current densities and voltages require considering that AAR (Alkali Aggregate Reaction) will not take place. The anodes are only temporarily fixed to the concrete and a protective coating need to be applied upon completion. As it is illustrated from Figure 5, the anodes will attract the negatively charged chlorides while they are repelled at the same time by the cathode. The repelled chlorides are then deposited on the external electrolyte and the hydroxyls produced on the steel surface help to increase the alkalinity.

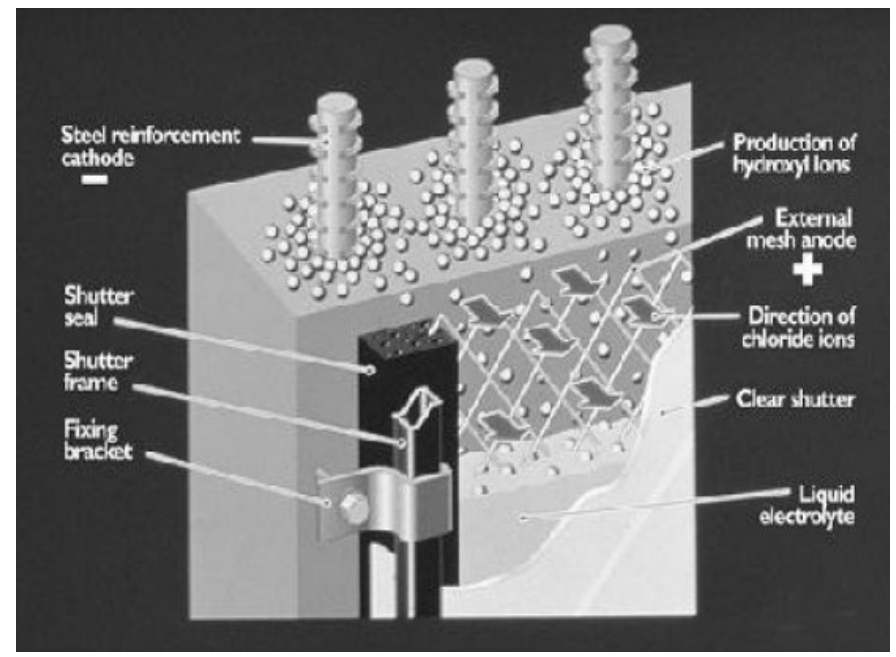

Figure 5: Electrochemical chloride extraction (Concrete Repair Association 2001) 


\subsection{Realkalisation}

This particular method aims to create a chemical reaction on the steel surface to neutralize the chlorides. Sodium carbonate $\left(\mathrm{Na}_{2} \mathrm{CO}_{3}\right)$ and potassium carbonate $\left(\mathrm{K}_{2} \mathrm{CO}_{3}\right)$ are the most common electrolytes used until today (Drewett 2000).

The hydroxyl ions produced, increases the alkalinity at the surface of the reinforcement, which repassivates the steel and prevents further corrosion. The typical duration of the application is 7 to 10 days and at a current density of $1000 \mathrm{~mA} / \mathrm{m}^{2}$. The depth of penetration of the electrolyte will depend on the concrete's permeability and the degree of dryness, with the less moist being the best. Figure 6 shows a schematic representation of such a system.

Because the reinforcement is polarised during the process, the most reliable technique to assess the performance is a $\mathrm{pH}$ test.

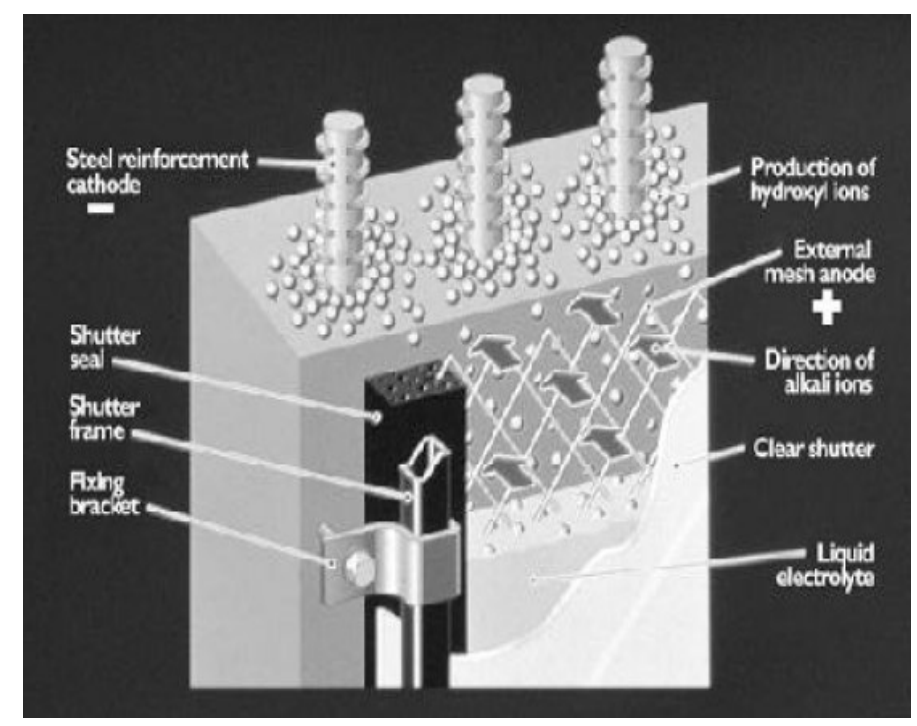

Figure 6: Electrochemical realkalization (Concrete Repair Association 2001)

\subsection{Galvanic Anodes}

Galvanic cathodic protection has been widely used mainly for the protection of underwater pipelines, oil platforms and even ship hulls. This particular method works on the principle that different metals produce different relative electrochemical potentials (Broomfield 2000).

A typical material used is zinc, or zinc coatings. The corrosion of the zinc anode can be expressed by equation 5 .

$$
\mathrm{Zn} \rightarrow \mathrm{Zn}^{2+}+2 e^{-}
$$

This action triggers a beneficial cathodic reaction on the steel surface which releases hydroxyl ions and therefore repels chlorides, as described by equation 6

$$
\mathrm{H}_{2} \mathrm{O}+1 / 2 \mathrm{O}_{2}+2 e^{-} \rightarrow 2 \mathrm{OH}^{-}
$$

The main disadvantage of galvanic anodes is their low driving voltage. In addition, galvanic cathodic protection relies on the electrolyte to carry the current, therefore subject to the concrete's resistivity. This is the main reason why they have been so successful on submerged structures, because water saturation provides a much lower resistivity of the electrolyte. In addition, the more active the initial corrosion is, the lower will be the resulting driving voltage of the galvanic anodes.

Although the aforementioned factors may sound limiting, galvanic anodes have significant advantages over traditional impressed current systems. Most important, there is no need for an external power supply, brings the costs of installation and maintenance down, monitoring is not essential, the current is self regulated from the anode and it can be directly connected to the cathode without the need of any complex wiring.

New materials have also been specified, such as aluminium and magnesium which promise to deliver higher potentials. However, they usually are more expensive than normal zinc and not widely used and their corrosion by-products are voluminous and may attack the concrete cover.

\section{CONCLUSIONS}

Electrochemical treatments can offer excellent results when applied properly. The contaminated but otherwise sound structure will be treated and continue to function as intended, increasing the probabilities reaching its design life.

Corrosion can be induced either due to carbonation of the concrete cover, cast in chlorides or chloride ingress through the pores of the structure. Reinforcement is normally passive and concrete provides a highly alkaline environment, thus developing a passive protective film.

A current density higher than 1 or $2 \mathrm{~mA} / \mathrm{m}^{2}$ is considered to be significant and a prevention plan should be developed. Typical chloride threshold levels range between 0.2 and $2.5 \%$ by weight of cement. The water to cement ratio will also affect the threshold.

Patch repairs have been widely used in the past, but in some cases with disappointing results. In cases of cast-in chlorides, the fresh alkaline mortar will probably worsen the overall corrosion stability. Where carbonation is the main cause of the problem and it has not reached a depth behind the reinforcement, it probably still remains the most cost effective solution.

Impressed current cathodic protection has been the main component of the repair and maintenance strategy on bridge structures. It provides a long term protection and the current output can be regulated to meet the performance of the system. However, this 
method requires availability of a constant power supply, significant electrical wiring and periodic monitoring of the system.

Galvanic anodes instead have low installation and maintenance costs and provide an alternative strategy for remote areas where a DC supply is not readily available. Uncontrolled anode-steel shorts present no risk to system function and stray current corrosion of discontinuous steel is limited. While the technology currently available is generally less powerful than impressed current, sacrificial anodes can be applied to areas of need.

Additionally, they can provide a cost efficient solution, when the specified anodes have a long serviceable life and the corrosion extent is not great. Generally, the technology is better used when it forms part of an overall corrosion arrest strategy.

A hybrid technique uses galvanic anodes both in an impressed current and a sacrificial role. Any future corrosion risk can be managed by applying a brief impressed current treatment to arrest the corrosion process and thereafter continue protection by means of sacrificial corrosion.

Realkalization and chloride extraction are temporarily techniques part of an overall management strategy and they do not require the extensive permanent installation of a traditional impressed current cathodic protection. However, they require the application of high current densities contrary to the impressed current cathodic protection.

In general, design and detailing of electrochemical treatment systems needs to consider the risk of failure in current distribution and output to arrest ongoing corrosion. Reinforcement corrosion in high resistivity concrete presents a particularly challenging problem.

Concluding, all the aforementioned corrosion arrest mechanisms are aimed to arrest corrosion and prevent further deterioration of the structure and by no means will they replace the already lost section.

\section{REFERENCES}

Breit, W. \& Schiessl, P. 1998. Concrete Durability. ACI SP 170. Detroit: American Concrete Institute: 363.

Broomfield, JP. 1997. Corrosion of steel in concrete, understanding, investigation and repair. London, UK: E \& FN Spon.

Broomfield, JP. 2000. The principles and practice of galvanic cathodic protection for reinforced concrete structures. Monograph No: 6. Corrosion Prevention Association.

BS8110: Structural use of concrete, Part 1: Code of practice for design and construction. British Standards Institution, London 1997.

Buenfeld, NR., Glass, GK., Hassanei, AM. \& Zhang J-Z. 1998. Chloride transport in concrete subjected to an electric field. Journal of Materials in Civil Engineering: 10(4): 220-228.

Concrete Repair Association 2001. Electrochemical repair using realkalisation and chloride extraction techniques.

Davison, N., Glass, G. \& Roberts, A. Hybrid Electrochemical treatment applied to corrosion damaged concrete structures. url:<

http://www.cptech.co.uk/Hybrid\%20Treatment\%20Paper.pdf > Accessed: 26 January 2008.

Drewett, J. 2000. An introduction to electrochemical rehabilitation techniques. Monograph No:2 . Corrosion Prevention Association.

Everett, L.H. \& Tradeaway, K.W.J 1980. Deterioration due to corrosion in reinforced concrete. Corr. Prevent. Control. Garston, Building Research Establishment. BRE Information Paper 12/80.

Glass, G.K. \& Buenfeld, N.R. 1997. The presentation of the chloride threshold level for corrosion of steel in concrete. Corrosion Science: 39(5): 1001-1013.

Glass, G.K., Reddy, B. \& Buenfeld, N.R. 1999. The inhibitive properties of concrete in a chloride containing environment. 14th International Corrosion Congress, Cape Town, September 1999: Paper No 47.1.

Glass, G.K., Reddy, B. \& Buenfeld, N.R. 2000. The participation of bound chloride in passive film breakdown on steel in concrete, Corrosion Science, 42, 2013-2021.

Glass, G.K. \& Reddy, B. 2002. The influence of the steel concrete interface on the risk of chloride induced corrosion initiation. In COST 521: Final Single Project Reports, UK6, pp. $227-232$.

Glass, G.K., Davison, N. \& Roberts, A. 2006. Pit realkalisation and its role in the electrochemical repair of reinforced concrete. Journal of Corrosion Science and Engineering, 9, paper 10.

Glass, G.K., Reddy, B. \& Clark, L.A. 2007. Towards rendering steel-reinforced concrete immune to chloride-induced corrosion. Proc. of the Institution of Civil Engineers. Construction Materials, Paper 700014.

Gowers, K.R. \& Millard, S.G. 1999. Electrochemical techniques for corrosion assessment of reinforced concrete structures. Proceedings of the Institution of Civil Engineers - Structures and Buildings: 134(2): 129-137.

Manning, D.G. et al. Corrosion of metals in concrete. American Concrete Institute Journal. Proceedings. Vol. 82, No.1. 1985. pp.3-32. Report 22R-85

Marcotte, T.D., Hansson, C.M. \& Hope, B.B. 1999. The effect of the electrochemical chloride extraction treatment on steel-reinforced mortar Part II - Microstructural characterization. Cement and Concrete Research. 29, 1561-1568.

Page, C.L. \& Tradeaway, K.W.J. 1982 Aspects of the electrochemistry of steel in concrete. Nature, 297, No. 5862, 109115.

Page, C.L. \& Sergi, G. 2000. Developments in cathodic protection applied to reinforced concrete. Journal of Materials in Civil Engineering (ASCE): 12(1): 8-15.

Parrott, LJ. 1987. A review of carbonation in reinforced concrete. Cement and Concrete Association.

Sergi, G., Page, C.L. \& Thompson, D.M. 1991. Materials and Structures. 24, 359.

Weber, W.J., McGinley, P.M. \& Katz, L.E. 1991. The nature and effects of absorption process in subsurface systems. In: Bear J \& Corapcioglu MY (eds) Transport process in porous media. NATO ASI Series E: Applied Sciences. Vol. 202. Netherlands: Kluwer. 543-582. 